\title{
Novel zirconium containing cage type silicate (Zr-KIT-5): An efficient Friedel-Crafts alkylation catalyst
}

\author{
Anand Ramanathan ${ }^{\mathrm{a}}$, Hongda Zhu ${ }^{\mathrm{a}, \mathrm{b}}$, Rajamanickam Maheswari ${ }^{\mathrm{a}, \mathrm{c}}$, Bala Subramaniam ${ }^{\mathrm{a}, \mathrm{b}, *}$ \\ ${ }^{a}$ Center for Environmentally Beneficial Catalysis, The University of Kansas, Lawrence, KS 66047, USA \\ ${ }^{b}$ Department of Chemical and Petroleum Engineering, The University of Kansas, Lawrence, KS 66045, USA \\ ${ }^{\mathrm{c}}$ Department of Chemistry, Anna University, Chennai 600025, India
}

\section{A R T I C L E I N F O}

\section{Article history:}

Available online $\mathrm{xxxx}$

\section{Keywords:}

KIT-5

Zirconium

Friedel-Crafts alkylation

Anisole

Benzyl alcohol
G R A P H I C A L A B S T R A C T

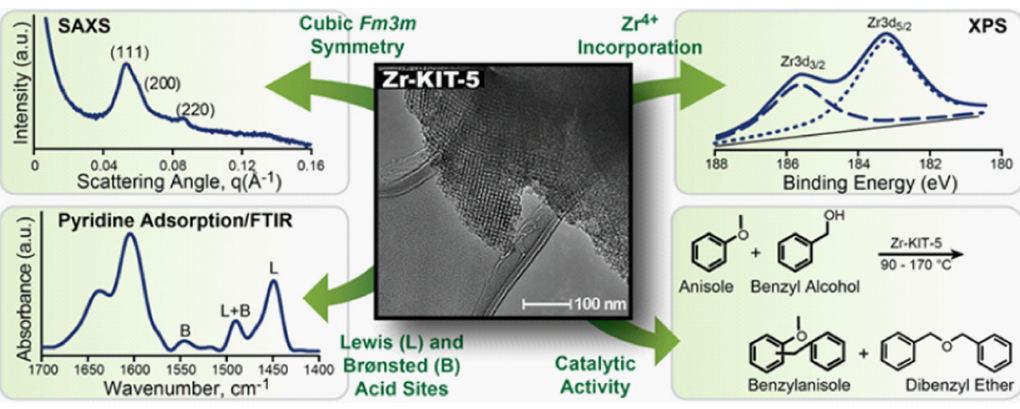

\begin{abstract}
A B S T R A C T
Zirconium was successfully incorporated into cubic KIT-5 mesoporous silicate by direct hydrothermal synthesis employing F127 triblock copolymer as the structure-directing agent. The Zr-KIT-5 materials exhibit relatively high specific surface area $\left(\sim 1000 \mathrm{~m}^{2} / \mathrm{g}\right)$ and pore volumes $\left(0.7-0.8 \mathrm{~cm}^{3} / \mathrm{g}\right)$, with an average cage diameter of approximately $8.8 \mathrm{~nm}$ as evidenced from $\mathrm{N}_{2}$ sorption and HR-TEM results. Diffuse reflectance UV-Vis spectroscopy and XPS studies reveal framework $\mathrm{Zr}^{4+}$ species that result in the formation of predominantly Lewis acid sites and some Brønsted acid sites, both of which increase with $\mathrm{Zr}$ content. The Zr-KIT-5 materials are shown to be highly active and stable catalysts for anisole benzylation with benzyl alcohol (BzOH) forming monobenzylated products (mainly ortho- and para-). It is shown that the benzylation activity depends mainly on the number and nature of the acid sites. Zr-KIT-5 material is thus a promising and environmentally benign Friedel-Crafts alkylation catalyst with many potential applications.
\end{abstract}

(c) 2014 Elsevier B.V. All rights reserved.

\section{Introduction}

The Friedel-Crafts alkylation/acylation of aromatic compounds, an important reaction in organic synthesis, is commonly carried out in the presence of homogeneous acid catalysts (e.g. $\mathrm{AlCl}_{3}$,

\footnotetext{
* Corresponding author at: Department of Chemical and Petroleum Engineering, The University of Kansas, Lawrence, KS 66045, USA. Tel.: +1 785864 2903; fax: +1 7858646051 .

E-mail address: bsubramaniam@ku.edu (B. Subramaniam).
}

$\mathrm{BF}_{3}, \mathrm{H}_{2} \mathrm{SO}_{4}, \mathrm{HF}, \mathrm{H}_{3} \mathrm{PO}_{4}$ etc.) [1]. To overcome the acid handling and waste disposal problems associated with these catalysts, solid acid catalysts, most notably zeolites, [2] have been pursued as environmentally superior alternatives. Although zeolites have been shown to be highly active in the alkylation and/or acylation of aromatics with lower alcohols [3-6], their microporous nature creates diffusion limitations during the benzylation of aromatics and eventually leads to catalyst deactivation [7]. It has been shown that introducing redox functionality [8] or generating mesoporosity $[9,10]$ in these zeolites dramatically increases the benzylation 
activity [11]. However, the synthetic procedures associated with the formation of mesoporosity in zeolites are tedious. Ordered mesoporous silicate materials with tunable acidity are relatively easier to synthesize and have been shown to be active for benzylation reactions. For example, SBA-15 type materials containing $\mathrm{Al}$ [12] and Fe [13] have been reported to show facile benzylation activity. Interestingly, Fe-SBA-15 was found to be superior to Al-SBA-15 indicating that the redox functionality of Fe-based catalysts imparts surprisingly remarkable activity for this type of reaction [14].

In recent years, we have been engaged in the preparation of catalytic materials based on cubic ordered mesoporous silicates such as KIT-6 [15], KIT-5 [16] and SBA-16 [17]. Zirconium containing KIT-6 catalysts were shown to possess, almost exclusively, Lewis acid sites that are highly active and stable for the dehydration of isopropanol [18] and ethanol [19]. In this paper, we extend our synthesis methodology to incorporate $\mathrm{Zr}$ into KIT-5 material, presenting a detailed characterization of the structural properties and the nature of zirconium coordination within the KIT-5 framework. Like Zr-KIT-6 materials, these materials are also shown to possess Lewis acid sites that can be tuned with $\mathrm{Zr}$ loading. Unlike Zr-KIT-6 however, the Zr-KIT-5 materials also exhibit Brønsted acidity at higher $\mathrm{Zr}$ content.

Anisole benzylation is often deployed as a test reaction to understand the nature of acid sites in a catalyst system. In general, benzylation is carried out using benzyl chloride or benzyl alcohol as alkylating agent, the latter being environmentally advantageous as it produces water as side product. In the presence of Lewis acid sites, benzyl alcohol forms predominantly dibenzyl ether (DBE) [20]. In contrast, Brønsted acid sites [21-25] are reported to be responsible for the formation of alkylated products. The synthesized Zr-KIT-5 materials show facile and stable activity for anisole benzylation with benzyl alcohol. The effect of acidity on conversion and product selectivity are presented.

\section{Materials and methods}

\subsection{Synthesis of Zr-KIT-5}

The synthesis of Zr-KIT-5 materials was carried out with molar $\mathrm{Si} / \mathrm{Zr}$ ratios of 100,50 and 25, designated as Zr-KIT-5(100), Zr-KIT5(50) and Zr-KIT-5(25) respectively, were synthesized following an analogous procedure reported for the synthesis of tungsten incorporated KIT-5 materials [16] employing tetraethyl orthosilicate (TEOS 98\%, Aldrich) and required amounts of Zirconium(IV) oxychloride octahydrate (99.5\% Sigma-Aldrich) as the $\mathrm{Si}$ and $\mathrm{Zr}$ sources, respectively. Under the synthesis condition used, a high loading of $\mathrm{Zr}(\mathrm{Si} / \mathrm{Zr}=10)$ resulted in a highly viscous gel that upon drying and calcination yielded a heterogeneous material that was unlike the OMS materials obtained at lower $\mathrm{Zr}$ loadings. This suggests a non-homogenous dispersion of $\mathrm{ZrOx}$ species at such high $\mathrm{Zr}$ loadings that is undesired and hence was not considered for further studies.

\subsection{Characterizations of Zr-KIT-5}

Small Angle X-ray Scattering (SAXS) patterns were recorded on a Rigaku system with a S-MAX 3000 instrument using a Bede Scientific microfocus tube source operating at $45 \mathrm{kV}$ and $0.66 \mathrm{~mA}$. Powder X-ray diffraction patterns were collected on a Rigaku MiniFlex diffractometer with a $\mathrm{Cu} \mathrm{K}_{\alpha}$ irradiation source. The textural properties were evaluated from $\mathrm{N}_{2}$ physisorption isotherms at $-196{ }^{\circ} \mathrm{C}$ on a Quantachrome NOVA 2000e instrument. Scanning Electron Micrographs (SEM) and Transmission Electron Micrographs (TEM) were carried out on a Versa 3D dual beam
Scanning Electron Microscope/ Focused Ion Beam (FEI, Hillsboro, OR, USA) with a silicon drift EDX detector (Oxford Instruments, X-Max, UK) and FEI Tecnai F20 G2 X-Twin instruments respectively. Elemental analysis was performed on a Horiba Jobin Yvon JY 2000 ICP-OES instrument. Diffuse reflectance UV-Vis spectra were recorded in the $200-800 \mathrm{~nm}$ range at room temperature, using Spectralon (Labsphere, Inc) as the reference, with a PerkinElmer (Lambda 850) spectrophotometer equipped with a diffuse reflectance integrating sphere. X-ray photoelectron spectroscopy (XPS) data were recorded on a Physical Electronics PHI 5800 ESCA system with standard non-monochromatic Al X-rays (1486.6 eV) operated at $250 \mathrm{~W}$ and $15 \mathrm{kV}$ in a chamber pumped down to a pressure of approximately $1.0 \times 10^{-8}$ Torr. The curve fitting was done using XPSPEAK with constraints applied to peak position, area as well as FWHM (full width at half maximum). Temperature programmed ammonia desorption ( $\mathrm{NH}_{3}-\mathrm{TPD}$ ) was carried out in a Micromeritics Autochem 2910 instrument equipped with a Thermal Conductivity Detector (TCD). Pyridine FTIR spectra of Zr-KIT-5 samples were acquired by saturating the Zr-KIT-5 samples with pyridine, drying the samples at $100^{\circ} \mathrm{C}$ in vacuum to remove physisorbed pyridine and analyzing them in the DRIFT mode at $120^{\circ} \mathrm{C}$ using a TENSOR-27 FTIR system with PIKE diffuse IR attachment.

\subsection{Benzylation of anisole with benzyl alcohol}

In a typical reaction, benzyl alcohol $(1.08 \mathrm{~g}, 10 \mathrm{mmol})$, anisole ( $10.8 \mathrm{~g}, 100 \mathrm{mmol})$, dodecane $(0.34 \mathrm{~g}, 2 \mathrm{mmol}$, internal standard) and Zr-KIT-5 (100 mg) were charged into a $25 \mathrm{~mL}$ two-necked round bottom flask fitted with a reflux condenser. The reaction mixture was stirred with a magnetic stir bar under nitrogen atmosphere $(50 \mathrm{std} \mathrm{cc} / \mathrm{min})$ at the desired temperature (maintained with an oil-bath) for a period of $6 \mathrm{~h}$. Samples were withdrawn periodically and analyzed on a Varian CP-3800 GC equipped with ZB-Wax capillary column $(25 \mathrm{~m} \times 0.32 \mathrm{~mm} \times 0.2 \mu \mathrm{m})$ and FID. The $C$ balance based on analysis of liquid phase products was nearly $100 \pm 2.5 \%$

\section{Results and discussion}

\subsection{Characterization of Zr-KIT-5}

SAXS patterns of Zr-KIT-5 samples as compared to a purely siliceous Si-KIT-5 are shown in Fig. 1. Reflections characteristic of face centered close-packed cubic lattice with $F m 3 m$ symmetry (111), (200) and (220) were observed for Si-KIT-5 and Zr-KIT-5 samples, with no significant changes in the intensity of these peaks up to $\mathrm{Si} / \mathrm{Zr}$ ratio of 50 [16,26-28]. However, a drastic decrease in the peak intensity (with peak broadening) was observed at increasing

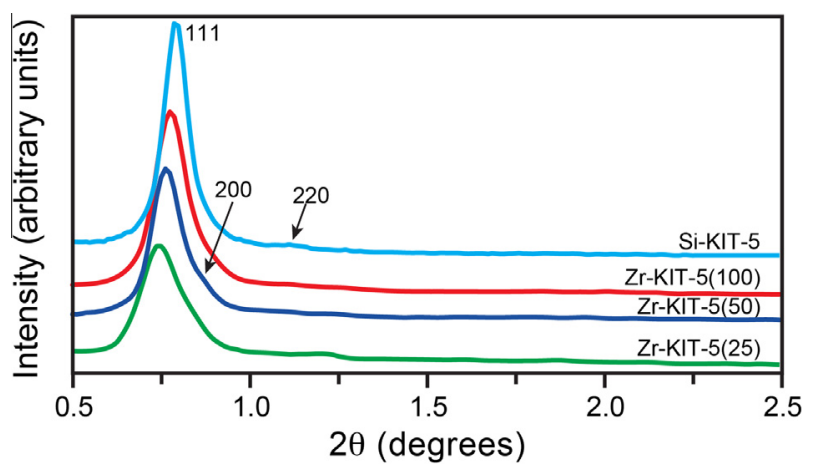

Fig. 1. SAXS patterns of Zr-KIT-5 materials compared with Si-KIT-5. 
Table 1

Physicochemical characteristics of calcined Zr-KIT-5 samples with different zirconium content.

\begin{tabular}{|c|c|c|c|c|c|c|c|}
\hline KIT-5 (Si/Zr) $)^{\mathrm{a}}$ & $\mathrm{Si} / \mathrm{Zr}^{\mathrm{b}}$ & $\mathrm{Zr}(\mathrm{wt} \%)$ & $a_{0}{ }^{\mathrm{c}}(\mathrm{nm})$ & $S_{\mathrm{BET}}{ }^{\mathrm{d}}\left(\mathrm{m}^{2} / \mathrm{g}\right)$ & $V_{\mathrm{tp}}{ }^{\mathrm{e}}(\mathrm{cc} / \mathrm{g})$ & $V_{\mathrm{mp}}^{\mathrm{f}}(\mathrm{cc} / \mathrm{g})$ & $d_{\mathrm{P}, \mathrm{NLDFT}^{\mathrm{g}}}(\mathrm{nm})$ \\
\hline Si-KIT-5 & - & & 19.7 & 1056 & 0.81 & 0.29 & 8.8 \\
\hline Zr-KIT-5(100) & 96 & 1.6 & 20.4 & 1018 & 0.71 & 0.28 & 8.8 \\
\hline Zr-KIT-5(50) & 51 & 2.9 & 20.9 & 1011 & 0.73 & 0.19 & 8.8 \\
\hline Zr-KIT-5(25) & 25 & 5.7 & 20.3 & 971 & 0.81 & 0.03 & 8.8 \\
\hline
\end{tabular}

a Molar ratio in the synthesis gel.

b Actual molar ratio in sample determined by ICP-OES.

c $a_{0}=\mathrm{d}_{111} \sqrt{3}$.

d $S_{\mathrm{BET}}=$ specific surface area determined using Brunauer-Emmett-Teller (BET) equation from adsorption isotherm at $P / P_{0}$ between 0.05 and 0.30 .

e $V_{\text {tp }}=$ total pore volume at $0.99 P / P_{0}$.

${ }^{\mathrm{f}} V_{\mathrm{mp}}=$ micropore volume.

g $d_{\mathrm{P}, \mathrm{NLDFT}}=$ determined using NLDFT kernel developed for silica exhibiting cylindrical/spherical pore geometry.

Zr contents [e.g. Zr-KIT-5(25)] suggesting some decrease in long range ordering in this sample. Unit cell parameters derived from (111) reflections (Table 1 ) are typical of those previously observed for KIT-5 type materials [16,28-30]. A slight increase in the unit cell parameter was observed for Zr-KIT-5 samples as compared to Si-KIT-5 [16]. This increase is attributed to $\mathrm{Zr}$ incorporation in these samples, resulting in the replacement of $\mathrm{Si}^{4+}$ ions by $\mathrm{Zr}^{4+}$ ions with higher atomic radius. Elemental analysis (via ICP OES) showed that the $\mathrm{Si} / \mathrm{Zr}$ ratios in the calcined $\mathrm{Zr}$-KIT-5 samples are almost identical to those in the initial synthesis gel.

Nitrogen physisorption isotherms of Zr-KIT-5 and Si-KIT-5 samples are shown in Fig. 2a. Textural properties obtained from $\mathrm{N}_{2}$ physisorption studies are summarized in Table 1 . All KIT-5 samples showed type IV adsorption isotherm with sharp capillary condensations occurring between 0.60 and $0.70 P / P_{0}$ and a broad H2-type hysteresis loop with desorption occurring at $\sim 0.47 \mathrm{P} / P_{0}$. Results are in good agreement with those reported for KIT-5 type materials [16,28-30]. The shifted onset of desorption to much lower $P / P_{0}$ values is attributed to the presence of smaller pore windows. Such isotherms are typical of ordered mesoporous materials possessing large uniform cage-like pores. A significant change in the slope of the capillary condensation step was evidenced at increased $\mathrm{Zr}$
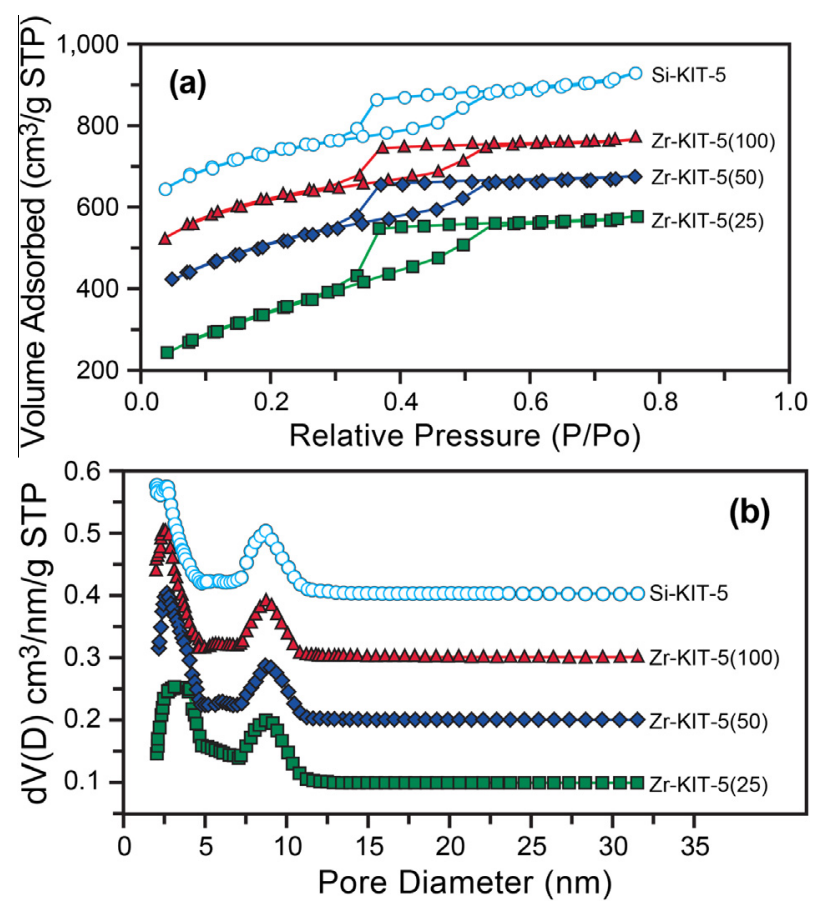

Fig. 2. (a) Nitrogen physisorption isotherms, and (b) pore size distributions, for ZrKIT-5 and Si-KIT-5. content. This is reflected in the micropore volume measurement by the t-plot method (Table 1), which decreased at increasing $\mathrm{Zr}$ content. The high specific surface area observed for the parent Si-KIT-5 sample similarly decreased progressively with an increase in $\mathrm{Zr}$ loading.

The pore size distribution (estimated using NLDFT adsorption branch kernel developed for silica materials exhibiting either cylindrical or spherical pore geometry available in the Autosorb software) showed a bimodal distribution for all the KIT-5 samples [16,31] (Fig. 2b). The cage diameter of the primary mesopore is estimated to be approximately $8.8 \mathrm{~nm}$. The presence of additional mesopores centered at approximately $2.4-2.8 \mathrm{~nm}$ is attributed to the entrance channels to the primary mesopore cages. Similar observation was also made in W-KIT-5 samples reported earlier by us [16].

Transmission electron microscopy images for representative Zr-KIT-5 samples are shown in Fig. 3. Cubic three-dimensional mesoporous structures with a high degree of long-range ordering, typical of $\mathrm{Fm} 3 \mathrm{~m}$ structures, are clearly observed [16,31]. In addition, a homogeneous distribution of Zr species in Zr-KIT-5(25) sample can be seen in the electron mapping of a TEM image (see Fig. 4). The weight percentage of $\mathrm{Zr}$ estimated from this image is approximately 5.6 , which is very close to that measured from ICP-OES (5.7\%, see Table 1). We also performed the dispersion of $\mathrm{Zr}$ species in a fairly larger area in dual beam FIB/SEM and the results are presented in Fig. 5. A good agreement of $6.3 \mathrm{wt} \% \mathrm{Zr}$ was obtained from the EDX analysis and a homogeneous dispersion of $\mathrm{Zr}$ was also noticed from electron mapping.

XRD patterns of calcined Zr-KIT-5 and Si-KIT-5 samples in the high angle region $\left(2 \theta=10-80^{\circ}\right)$ were compared with $\mathrm{ZrO}_{2}$ nanopowder (Aldrich) as depicted in Fig. 6 . The broad diffraction peak centered at $2 \theta$ values of approximately $18-22^{\circ}$ corresponds to the amorphous silica walls of Zr-KIT-5 materials, as also observed in Si-KIT-5. No characteristic reflections corresponding to bulk zirconia could be observed in Zr-KIT-5 (100, 50 and 25) samples, suggesting a homogenous dispersion of $\mathrm{Zr}$ species in samples with low $\mathrm{Zr}$ loading, confirming the TEM and SEM analyses.

The diffuse reflectance UV-Vis spectra of Zr-KIT-5 materials are shown in Fig. 7. Distinct absorption bands around $203 \mathrm{~nm}$ and $209 \mathrm{~nm}$ were observed for the Zr-KIT-5(100 and 50) and $\mathrm{Zr-KIT-5(25)}$ samples, respectively. In addition, weak absorption bands around $230 \mathrm{~nm}$ and $280 \mathrm{~nm}$ were observed in all Zr-KIT-5 samples. In general, the absorption band around $205-215 \mathrm{~nm}$, previously observed for $\mathrm{Zr}$-containing mesoporous silicates, is attributed to ligand-to-metal charge transfer (LMCT) from an $\mathrm{O}^{2-}$ to an isolated $\mathrm{Zr}^{4+}$ ion in a tetrahedral configuration [32-36]. Based on these findings, we conclude that most of the $\mathrm{Zr}$ is incorporated as $\mathrm{Zr}^{4+}$ ion in a tetrahedral configuration in Zr-KIT-5 materials. The weak absorption band at $230 \mathrm{~nm}$ is attributed to LMCT of $\mathrm{O}^{2-}$ to $\mathrm{Zr}^{4+}$ typically present in $\mathrm{ZrO}_{2}$ or $\mathrm{Zr}(\mathrm{IV})$ silicate [32-34,36] and the band at $280 \mathrm{~nm}$ samples may be attributed to the presence of 

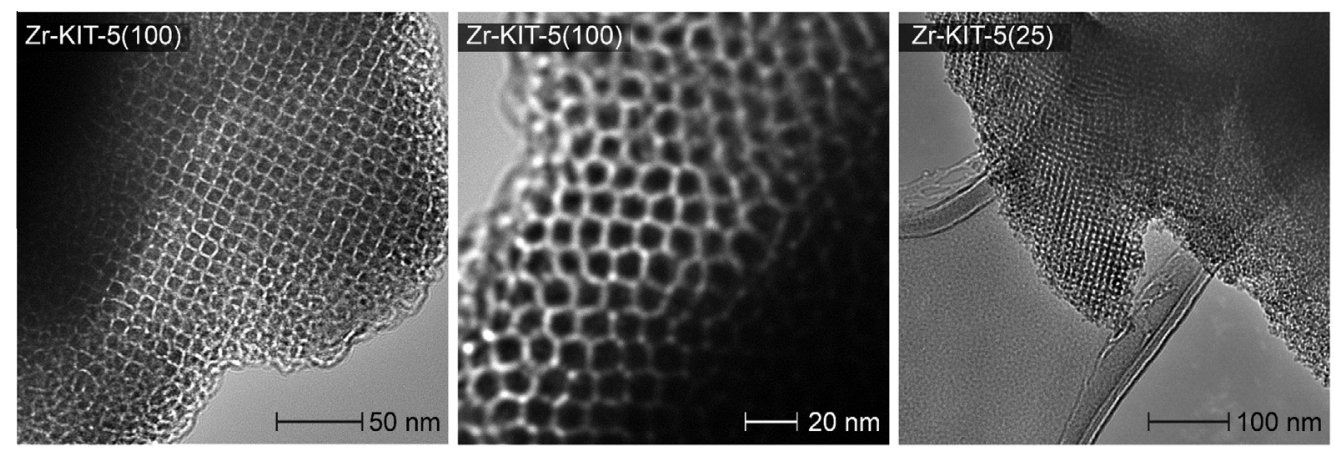

Fig. 3. Representative transmission electron microscopy images of Zr-KIT-5 (Si/Zr).
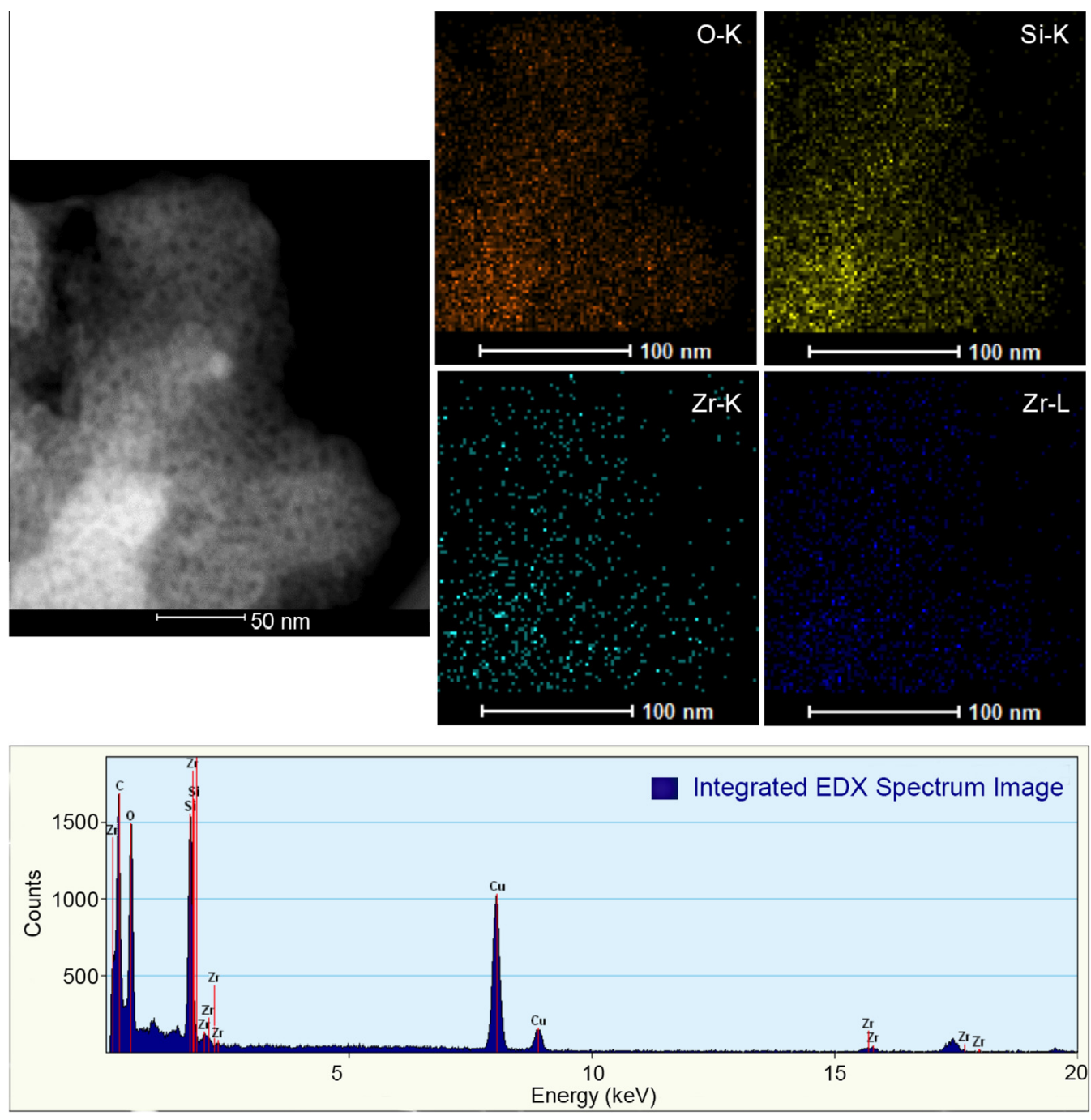

Fig. 4. STEM image of Zr-KIT-5(25) and its corresponding electron mapping and EDX analyses.

homogeneously distributed $\mathrm{ZrO}_{2}$ nanoparticles [32-36]. The absence of reflection peaks due to crystalline $\mathrm{ZrO}_{2}$ clusters in the wide angle XRD for Zr-KIT-5(100, 50 and 25, Fig. 6) suggests that either the particle size and/or the concentration of $\mathrm{ZrO}_{2}$ clusters might be relatively low in these samples. Further, FTIR spectra of $\mathrm{Zr}-\mathrm{KIT}-5$ in the region of $1800-600 \mathrm{~cm}^{-1}$ (Fig. S1) reveal vibration bands associated with asymmetric and symmetric stretching vibrations of Si-O-Si bond at 1228, 1082 and $804 \mathrm{~cm}^{-1}$ respectively. The bending vibration mode of $\mathrm{Si}-\mathrm{O}-\mathrm{H}$ is observed at
$1650 \mathrm{~cm}^{-1}$. Besides, the formation of $\mathrm{Si}-\mathrm{O}-\mathrm{Zr}$ units is confirmed by the characteristic vibration band at $966 \mathrm{~cm}^{-1}$ [37].

Fig. 8 shows the XPS spectra of Zr-KIT-5(25) for Zr3d lines $\left(3 d_{3 / 2}\right.$ and $3 d_{5 / 2}$ ). The binding energy (BE) obtained for $\mathrm{Zr} 3 \mathrm{~d}_{5 / 2}$ is $183.3 \mathrm{eV}$ which is higher than the values reported for $\mathrm{ZrO}_{2}$ (182.5) [38]. Bosman et al. reported an increase in $\mathrm{BE}$ of $\mathrm{Zr} 3 \mathrm{~d}_{5 / 2}$ of about $0.6-1.2 \mathrm{eV}$ with a decrease in $\mathrm{Zr}$ loading (in $\mathrm{SiO}_{2}-\mathrm{ZrO}_{2}$ mixed oxides) compared to pure $\mathrm{ZrO}_{2}$ [38]. The observed $\mathrm{BE}$ values for $\mathrm{Zr}-\mathrm{KIT}-5$ are found to be close to those reported for $\mathrm{Zr}^{4+}$

Please cite this article in press as: A. Ramanathan et al., Novel zirconium containing cage type silicate (Zr-KIT-5): An efficient Friedel-Crafts alkylation catalyst, Chem. Eng. J. (2014), http://dx.doi.org/10.1016/j.cej.2014.11.099 

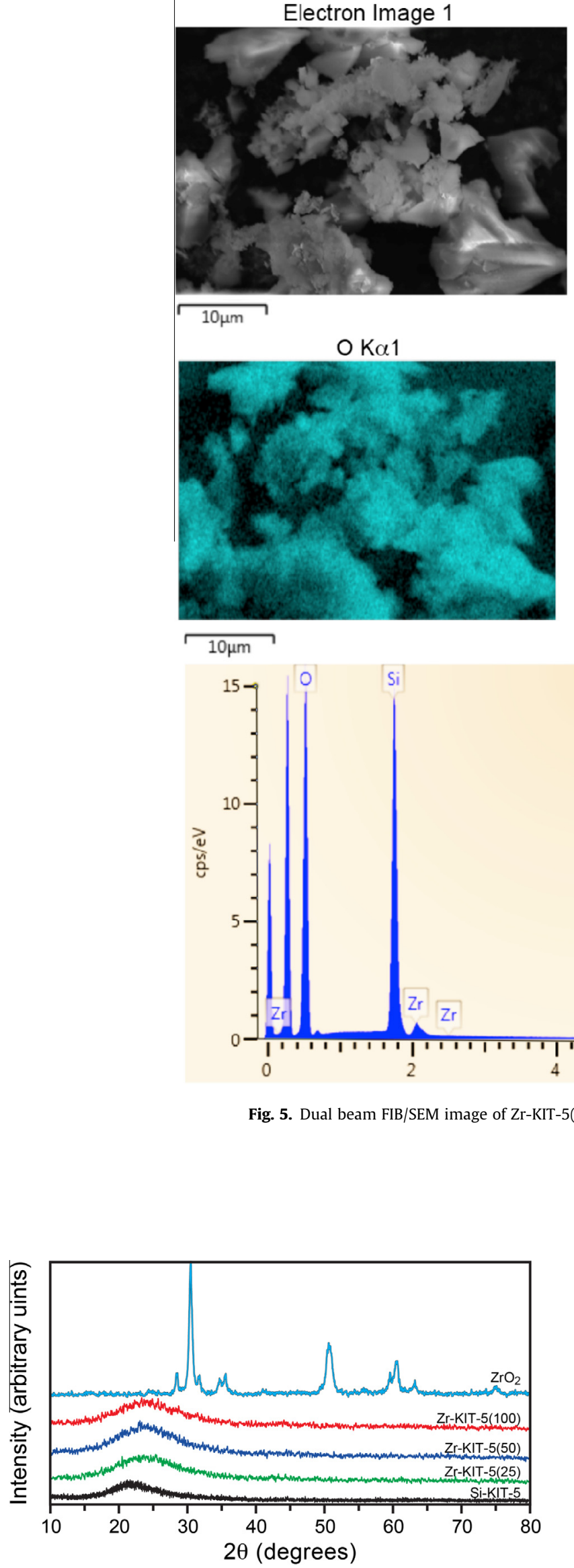
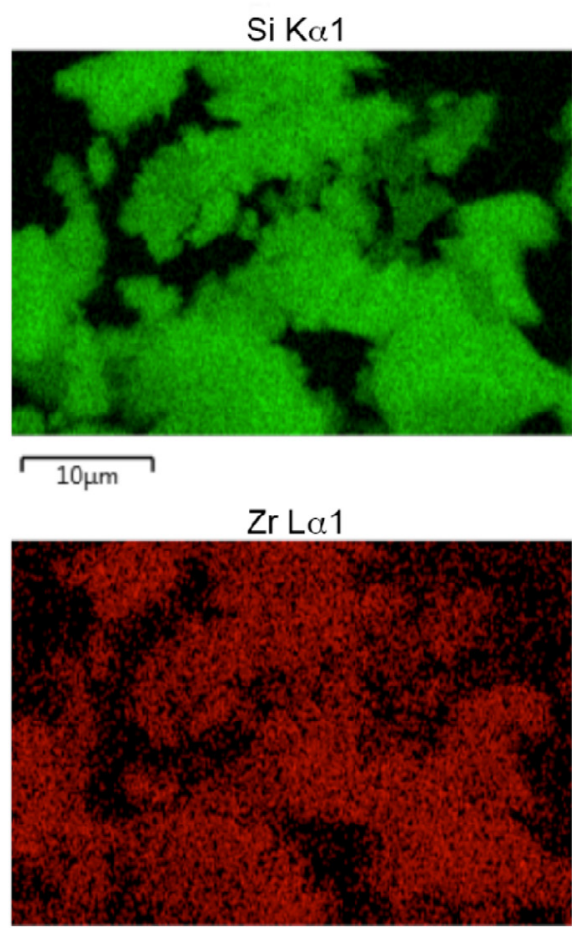

$10 \mu \mathrm{m}$

Map Sum Spectrum

Wt $\%$ o

51.30 .1

$42.3 \quad 0.1$

$6.3 \quad 0.1$
Fig. 6. Wide angle XRD of $\mathrm{Zr}-\mathrm{KIT}-5$ samples compared with commercial $\mathrm{ZrO}_{2}$

Please cite this article in press as: A. Ramanathan et al., Novel zirconium containing cage type silicate (Zr-KIT-5): An efficient Friedel-Crafts alkylation catalyst, Chem. Eng. J. (2014), http://dx.doi.org/10.1016/j.cej.2014.11.099

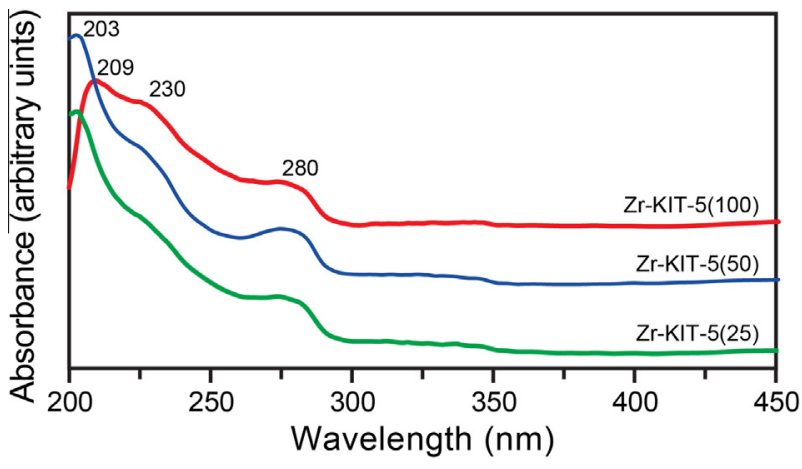

Fig. 7. Diffuse reflectance UV-Vis spectra of Zr-KIT-5. 


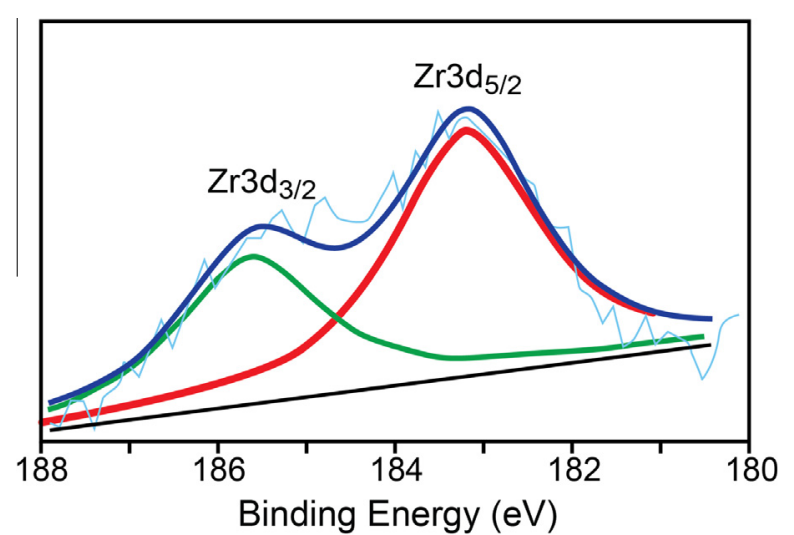

Fig. 8. The XPS spectra of $\mathrm{Zr}-\mathrm{KIT}-5(25)$ suggesting $\mathrm{Zr}$ incorporation as $\mathrm{Zr}^{4+}$ ions in KIT-5 silica framework.

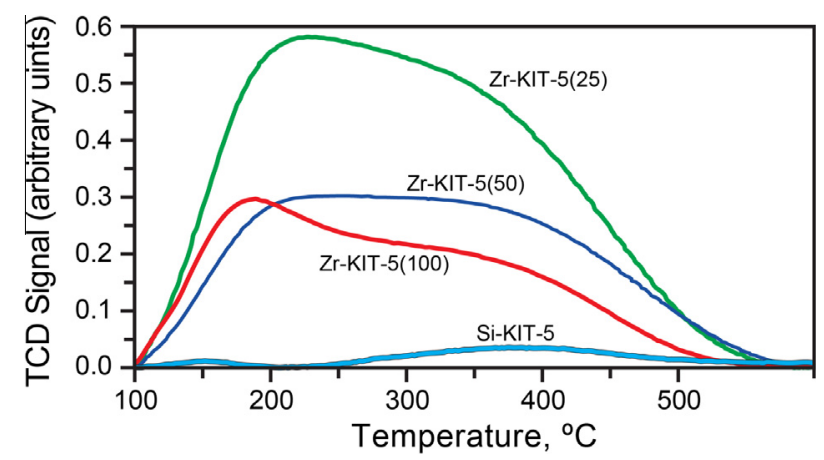

Fig. 9. Ammonia TPD profiles of Zr-KIT-5 and Si-KIT-5.

incorporated TUD-1 silicates [32,34], providing further evidence of $\mathrm{Zr}$ incorporation as $\mathrm{Zr}^{4+}$ ions in the KIT-5 silica framework.

To measure the acidity of Zr-KIT-5 samples, temperature programmed ammonia desorption studies ( $\left.\mathrm{NH}_{3}-\mathrm{TPD}\right)$ were performed, benchmarking the results with $\mathrm{Zr}$-free Si-KIT-5 sample. Ammonia TPD profiles are shown in Fig. 9. No significant ammonia desorption was observed for Si-KIT-5 (0.02 mmol $\left.\mathrm{NH}_{3} / \mathrm{g}\right)$. However, the total acidity increased significantly to $0.22 \mathrm{mmol} \mathrm{NH}_{3} / \mathrm{g}$ for Zr-KIT-5(100) upon incorporation of a small amount (1.6 wt\%) of $\mathrm{Zr}$ into KIT-5. The total number of acid sites increases with $\mathrm{Zr}$ content (see Table 2). FTIR spectra of adsorbed pyridine (measured at $120^{\circ} \mathrm{C}$ ) on Zr-KIT-5 samples (Fig. 10) confirmed the predominant presence of Lewis acid sites. The observed absorbance bands at around 1580 and $1440 \mathrm{~cm}^{-1}$ are attributed to pyridine adsorbed on Lewis (L) sites while those at $1480 \mathrm{~cm}^{-1}$ are assigned to a combination of Brønsted and Lewis $(B+L)$ acid sites. Protonated pyridine species, typically observed on Brønsted acid sites around $1545 \mathrm{~cm}^{-1}$, were weakly evident at low Zr loading [Zr-KIT-5(100)] and appear to increase with $\mathrm{Zr}$ content (see also Table 2 ). It has also been reported that the substitution of $\mathrm{Zr}^{4+}$ for $\mathrm{Si}^{4+}$ in the silica

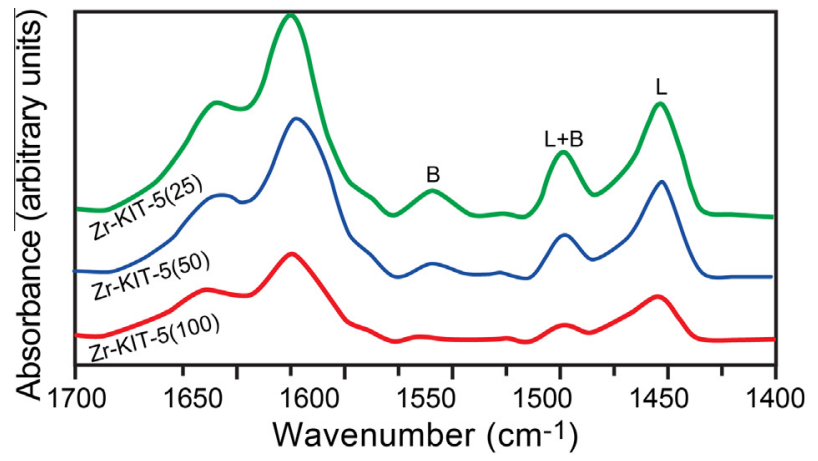

Fig. 10. FTIR spectra of adsorbed pyridine over Zr-KIT-5 at $120^{\circ} \mathrm{C}$.

framework can result in Brønsted acidity at the bridging oxygen due to differences in the charge density of the two ions [39].

\subsection{Benzylation of anisole over Zr-KIT-5}

In general, the liquid phase benzylation of anisole with benzyl alcohol (BzOH) over Zr-KIT-5 catalysts results in the formation of only monobenzylated compounds such as ortho-benzylanisole $(o-B A)$ and para-benzylanisole $(p-B A)$ as major products (Scheme 1). The initially formed dibenzyl ether (DBE) is further consumed for the formation of $o$-BA and $p$-BA. Only very minor amount of meta-benzylanisole ( $m$-BA) is observed. No significant $\mathrm{BzOH}$ conversion was noted when the reaction was performed without any catalyst (at $170{ }^{\circ} \mathrm{C}$ ) and also with Si-KIT-5 (at $130^{\circ} \mathrm{C}$ ).

Fig. 11a shows temporal $\mathrm{BzOH}$ (limiting reactant) conversion profiles at different temperatures using $100 \mathrm{mg}$ of Zr-KIT-5(25) catalyst. The corresponding product selectivities are given in Fig. 11 b. At $110{ }^{\circ} \mathrm{C}$, the $\mathrm{BzOH}$ conversion is only approximately $18 \%$ after $1 \mathrm{~h}$ and near complete conversion of $\mathrm{BzOH}$ is achieved after nearly $6 \mathrm{~h}$. Further increases in reaction temperature $\left(130-170{ }^{\circ} \mathrm{C}\right)$ markedly enhance the conversion rates, resulting in nearly total $\mathrm{BzOH}$ conversion within $30 \mathrm{~min}$ at $170{ }^{\circ} \mathrm{C}$. Moreover, the selectivities towards benzylated anisoles increase with reaction temperature (Fig. 11b). A significant amount of DBE is observed at lower reaction temperature (lower $\mathrm{BzOH}$ conversion), which also acts as an alkylating agent at higher temperatures thus improving selectivities towards o-BA and p-BA. The rate of DBE consumption (as an alkylating agent) is dictated by temperature. At lower temperatures ( 90 and $110^{\circ} \mathrm{C}$ ), the consumption rates are slow enough that it is possible to see its gradual evolution and consumption. At higher temperatures $\left(130^{\circ} \mathrm{C}\right.$ and beyond), the consumption rate (as an alkylating agent) increases to such an extent that the DBE produced is totally consumed during the run with corresponding increases in the alkylated product. A figure reflecting the temporal DBE consumption profiles at various temperatures is presented in the ESI (see Fig. S1). Interestingly, at all temperatures, the ratio of $o$-BA/ $p$-BA was observed to be between 1.07 and 1.12 .

Table 2

Variation of Lewis and Brønsted Acidities of Zr-KIT-5 samples with Zr content.

\begin{tabular}{|c|c|c|c|c|}
\hline Sample & Total acidity ${ }^{\mathrm{a}} \mathrm{NH}_{3} \mathrm{mmol} / \mathrm{g}$ & Lewis $(L)^{b}$ & Brønsted (B) ${ }^{\mathrm{b}}$ & $\mathrm{L} / \mathrm{B}$ ratio $^{\mathrm{c}}$ \\
\hline Zr-KIT-5(100) & 0.22 & 0.53 & 0.02 & 47.8 \\
\hline Zr-KIT-5(50) & 0.35 & 1.10 & 0.11 & 20.9 \\
\hline Zr-KIT-5(25) & 0.59 & 1.27 & 0.26 & 10.4 \\
\hline
\end{tabular}

a From ammonia TPD measurements.

b Relative areas estimated from FTIR spectra of adsorbed pyridine.

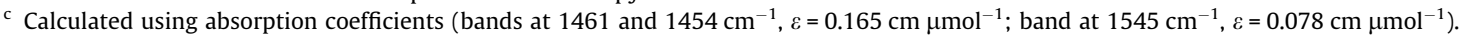




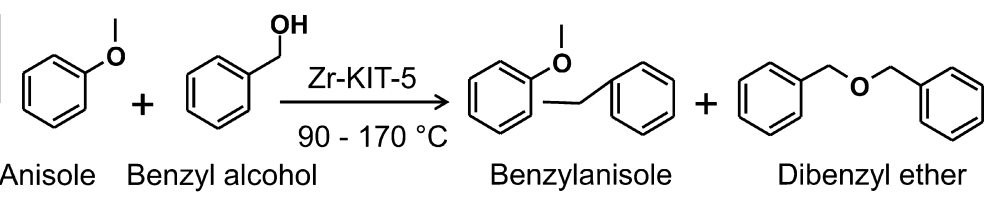

Scheme 1. Benzylation of anisole with benzyl alcohol over Zr-KIT-5.
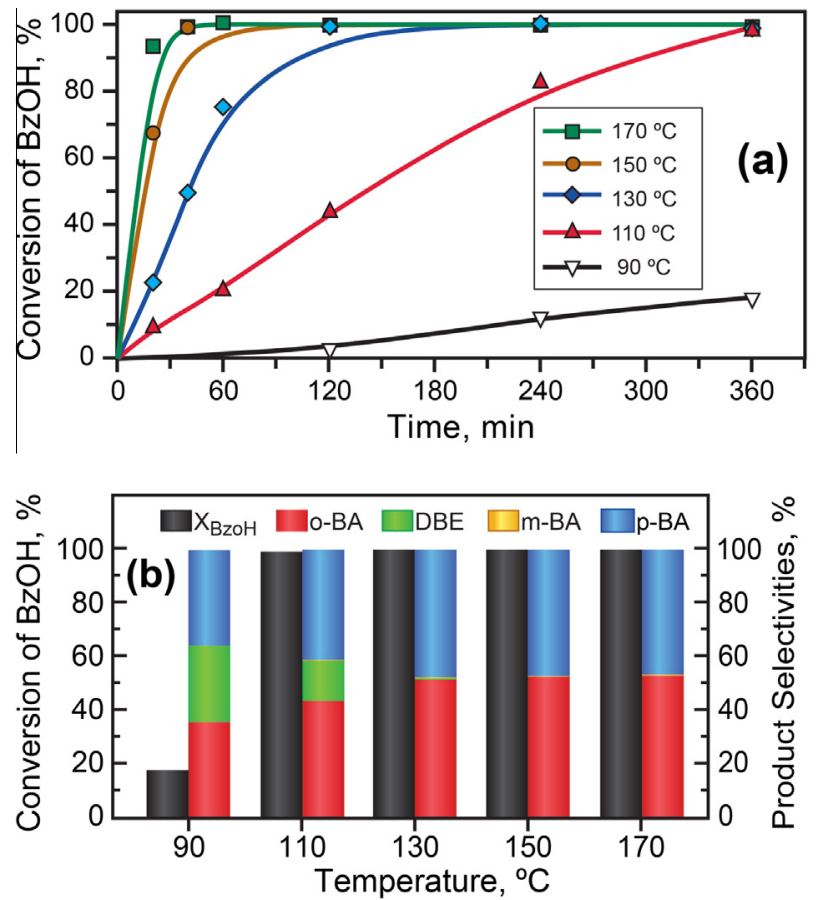

Fig. 11. Effect of temperature on (a) temporal $\mathrm{BzOH}$ conversion profiles, and (b) product selectivities at $6 \mathrm{~h}$ over Zr-KIT-5(25). Reaction conditions: anisole $=100 \mathrm{mmol}, \mathrm{BzOH}=10 \mathrm{mmol}$, dodecane $=2 \mathrm{mmol}$, catalyst $=100 \mathrm{mg}$.

Similarly, catalyst amount has a significant effect on conversion of $\mathrm{BzOH}$. With $25 \mathrm{mg}$ of $\mathrm{Zr}-\mathrm{KIT}-5(25)$ catalyst at $130{ }^{\circ} \mathrm{C}$, about $45 \%$ $\mathrm{BzOH}$ conversion is observed after $6 \mathrm{~h}$ of reaction (Fig. 12a). However, doubling this catalyst amount (to $50 \mathrm{mg}$ ) yields nearly total $\mathrm{BzOH}$ conversion in $6 \mathrm{~h}$. With $100 \mathrm{mg}$, complete conversion of $\mathrm{BzOH}$ is achieved in $2 \mathrm{~h}$ at $130^{\circ} \mathrm{C}$. The variation in catalyst amount also has an appreciable effect on product distribution (Fig. 12b). Although $100 \% \mathrm{BzOH}$ conversion is achieved with 50 and $100 \mathrm{mg}$ of catalyst, $\sim 17 \%$ DBE (unreacted) is observed with $50 \mathrm{mg}$ of catalyst. With $25 \mathrm{mg}$ of catalyst, the amount of DBE ( $\sim 28 \%$ ) is similar to that of $p$-BA $(\sim 34 \%)$. These results demonstrate the importance of the availability of acid sites to convert not only $\mathrm{BzOH}$ but also the DBE.

The conversion rate of $\mathrm{BzOH}$ decreases with increasing $\mathrm{BzOH}$ concentration (decreasing anisole excess) in the feed (Fig. 13a). Similar conversion profiles are observed for molar feed anisole/ $\mathrm{BzOH}$ ratios of 10 and 5 , reaching $\sim 100 \% \mathrm{BzOH}$ conversion in $2 \mathrm{~h}$ and $4 \mathrm{~h}$ min respectively. For anisole $/ \mathrm{BzOH}$ ratio of 2.5 , only $\sim 75 \% \mathrm{BzOH}$ was converted after $6 \mathrm{~h}$. The DBE formation (Fig. 13b) also increased with $\mathrm{BzOH}$ concentration (i.e. lower anisole/BzOH ratios), suggesting that the DBE formed by etherification is the primary product that acts as alkylating agent. Indeed, it was shown that DBE was preferentially formed over Lewis sites [20] and that formation of the ether is a faster reaction compared to the benzylation reaction [40].
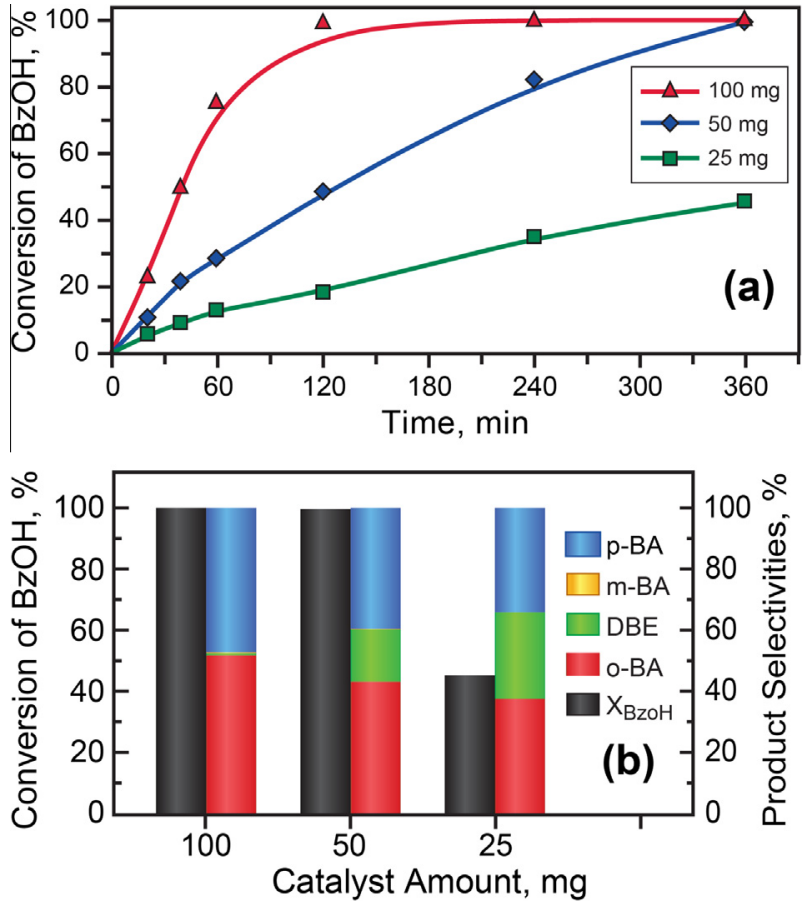

Fig. 12. Effect of Zr-KIT-5(25) catalyst amount on (a) temporal BzOH conversion profiles, and (b) product selectivities at $6 \mathrm{~h}$, at $130^{\circ} \mathrm{C}$. Reaction conditions: anisole $=100 \mathrm{mmol}, \mathrm{BzOH}=10 \mathrm{mmol}$, dodecane $=2 \mathrm{mmol}, T=130^{\circ} \mathrm{C}$.

The $\mathrm{Si} / \mathrm{Zr}$ ratio and the acidity of Zr-KIT-5 materials play a crucial role in the $\mathrm{BzOH}$ conversion and product distribution (Fig. 14a). Zr-KIT-5(100), having a lower number of acid sites (22 mmol $\mathrm{NH}_{3} / \mathrm{g}$ ), yields only $\sim 40 \% \mathrm{BzOH}$ conversion in $6 \mathrm{~h}$ with DBE as the major product ( $\sim 51 \%$ selectivity, see Fig. 14 b). In contrast, $\sim 98 \%$ $\mathrm{BzOH}$ conversion is observed with Zr-KIT-5(50) and 15\% DBE still remains after $6 \mathrm{~h}$ (Fig. 14b). The higher conversion rate of $\mathrm{BzOH}$ and DBE to form monobenzylated products over Zr-KIT-5(25) catalysts is clearly due to presence of a greater number of acid sites (both $\mathrm{B}$ and $\mathrm{L}$ sites) as compared to the other Zr-KIT-5 catalysts. As the $\mathrm{Zr}$ content is increased from 1.6 to $5.7 \mathrm{wt} \%$, the $\mathrm{L} / \mathrm{B}$ ratio decreases due to a steeper increase in the Brønsted acid sites relative to the Lewis acid sites. Similarly, the $\mathrm{BzOH}$ conversion normalized with respect to the total acid sites also increases as the $\mathrm{Zr}$ loading is varied (see Table 3, entries in rows 3-5). This clearly suggests that the nature of the acid sites plays a role in the observed conversion and selectivity profiles.

Comparison of the performance with literature reports (Table 4) clearly shows the superiority of Zr-KIT-5 over other microporous materials (HZSM-5 and H-Beta). The Zr-KIT-5 materials show higher catalytic activity at much lower temperature compared to Brønsted acidic catalysts such as $\mathrm{Nb}_{2} \mathrm{O}_{5}$, niobium phosphate or mesoporous $\mathrm{ZrPW}$. It also should be noted that at similar reaction temperature, complete conversion of $\mathrm{BzOH}$ was observed in shorter duration. Heteropoly acid catalysts are reported to catalyze 

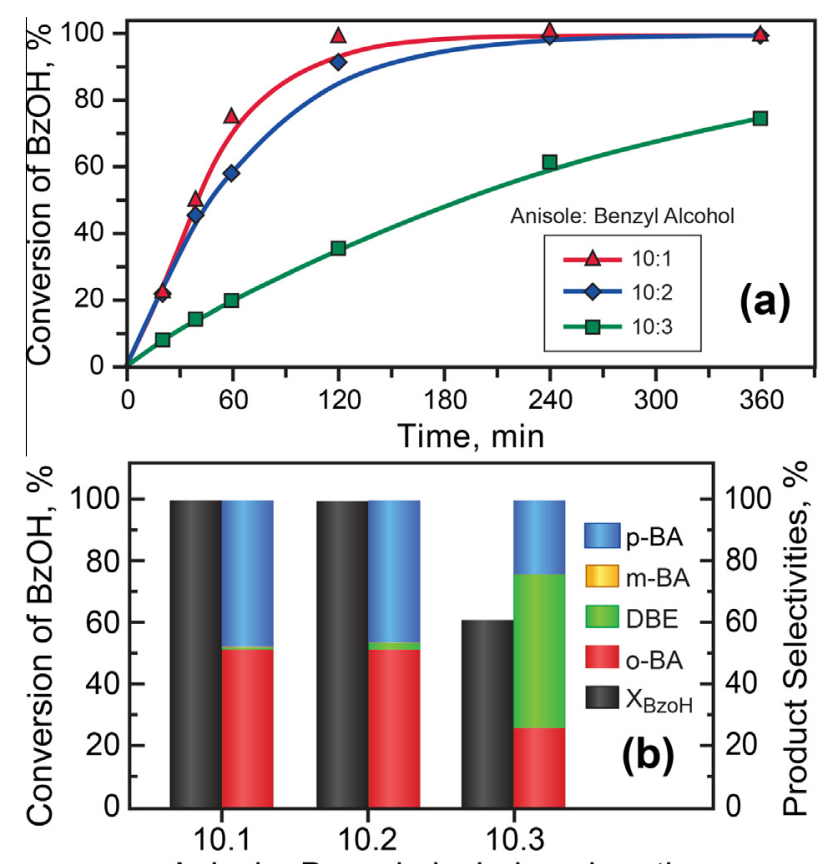

Anisole: Benzyl alcohol, mole ratio

Fig. 13. Effect of initial anisole to $\mathrm{BzOH}$ mole ratio on (a) temporal $\mathrm{BzOH}$ conversion profiles, and (b) product selectivities, at $130^{\circ} \mathrm{C}$ over Zr-KIT-5(25) catalyst.
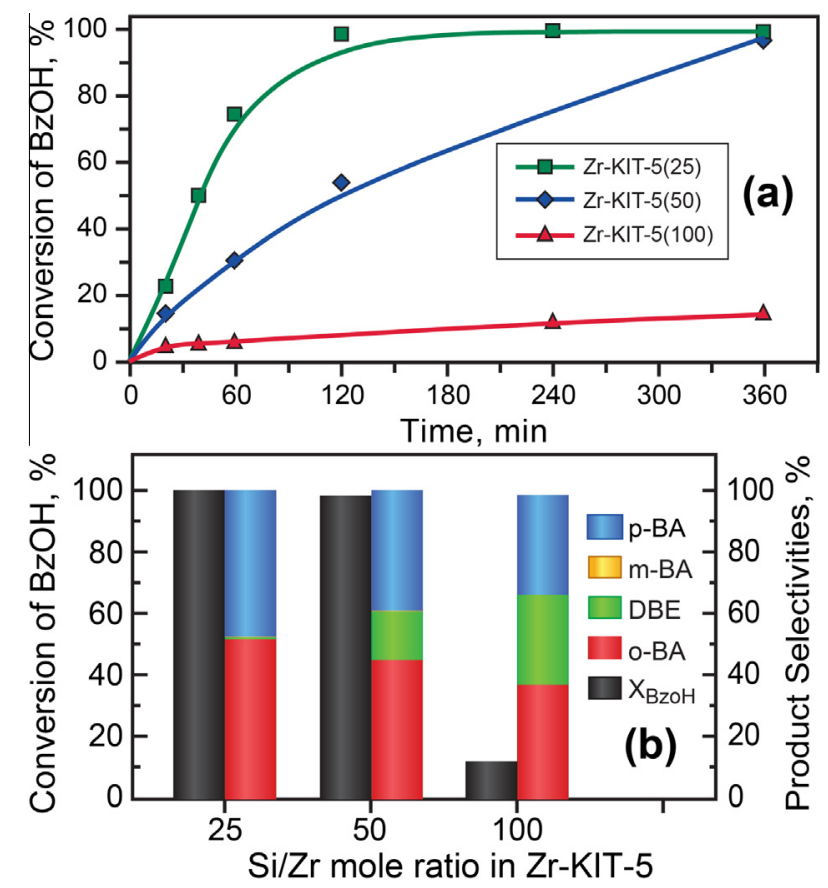

Fig. 14. Effect of $\mathrm{Si} / \mathrm{Zr}$ mole ratio on (a) temporal $\mathrm{BzOH}$ conversion profiles, and (b) product selectivities at $6 \mathrm{~h}$ at $130^{\circ} \mathrm{C}$; Reaction conditions: anisole $=100 \mathrm{mmol}$, $\mathrm{BzOH}=10 \mathrm{mmol}$, dodecane $=2 \mathrm{mmol}$.

anisole benzylation at even lower temperature $\left(80-120^{\circ} \mathrm{C}\right)$ possibly due to higher number of Brønsted acid sites. Nevertheless, the Zr-KIT-5 catalyst can be recycled multiple times without loss of activity (Fig. 15a). Although the temporal BzOH conversion profiles for the different recycle runs are similar, a mild increase in
Table 3

Dependence of anisole benzylation over Zr-KIT-5 catalysts on total number of acid sites. Reaction conditions: anisole $=100 \mathrm{mmol}, \mathrm{BzOH}=10 \mathrm{mmol}$, dodecane $=2 \mathrm{mmol}$, $T=130^{\circ} \mathrm{C}$.

\begin{tabular}{cccl}
\hline Zr-KIT-5(Si/Zr) & Cat. amt & $X_{\text {BzOH }}$ & $X_{\text {BzOH}} /$ acid sites $^{\text {a }}$ \\
\hline 25 & 25 & 5.4 & 36.7 \\
25 & 50 & 10.5 & 35.7 \\
25 & 100 & 22.2 & 37.6 \\
50 & 100 & 14.4 & 32.1 \\
100 & 100 & 8.1 & 21.8 \\
\hline
\end{tabular}

a Number of acid sites per g catalyst is listed in Table 2.

Table 4

Performance comparison of Zr-KIT-5 catalyst with literature data for anisole benzylation with benzyl alcohol.

\begin{tabular}{|c|c|c|c|c|c|c|}
\hline \multirow[t]{2}{*}{ Catalyst } & \multirow{2}{*}{${ }^{\mathrm{T}} \mathrm{C}$} & \multirow{2}{*}{$\begin{array}{l}t \\
\min \end{array}$} & \multirow[t]{2}{*}{$X_{\mathrm{BzOH}}$} & \multicolumn{3}{|c|}{ Selectivity (\%) } \\
\hline & & & & o-BA & $\mathrm{p}-\mathrm{BA}$ & DBE \\
\hline Zr-KIT-5(25) & 130 & 240 & 100 & 51.8 & 47.3 & 0.7 \\
\hline Zr-KIT-5(25) & 170 & $\sim 40$ & 100 & 52.6 & 46.9 & 0 \\
\hline $\mathrm{H}_{3} \mathrm{PO}_{4}-\mathrm{WO}_{3}-\mathrm{Nb}_{2} \mathrm{O}_{5}[22]$ & 80 & 180 & 100 & 94 & & 0.3 \\
\hline $25 \% \mathrm{TPA} / \mathrm{SnO}_{2}[40]$ & 120 & 90 & 95.12 & 33.56 & 42.26 & 24.17 \\
\hline ZSM-5 (HT) [11] & 100 & 60 & $\sim 30$ & - & - & - \\
\hline $\begin{array}{l}\text { MesoZSM-5(SO3H-CTAB)- } \\
\text { MW [11] }\end{array}$ & 100 & 60 & $\sim 100$ & - & - & - \\
\hline $\mathrm{Nb}_{2} \mathrm{O}_{5} / \mathrm{Al}_{2} \mathrm{O}_{3}[20]$ & 160 & 90 & 100 & 29.2 & 44.9 & 20.3 \\
\hline $\mathrm{Nb}_{2} \mathrm{O}_{5}[20]$ & 160 & 180 & 100 & 27.4 & 41.2 & 16.6 \\
\hline Niobium phosphate [41] & 160 & $<360$ & 100 & 34.3 & 53.1 & 5.2 \\
\hline M-ZrPW-20 [42] & 170 & 120 & 100 & $\sim 87$ & & \\
\hline H-Beta [42] & 170 & 120 & $\sim 63$ & $\sim 83$ & & \\
\hline H-ZSM5 [42] & 170 & 120 & $\sim 17$ & $\sim 65$ & & \\
\hline
\end{tabular}
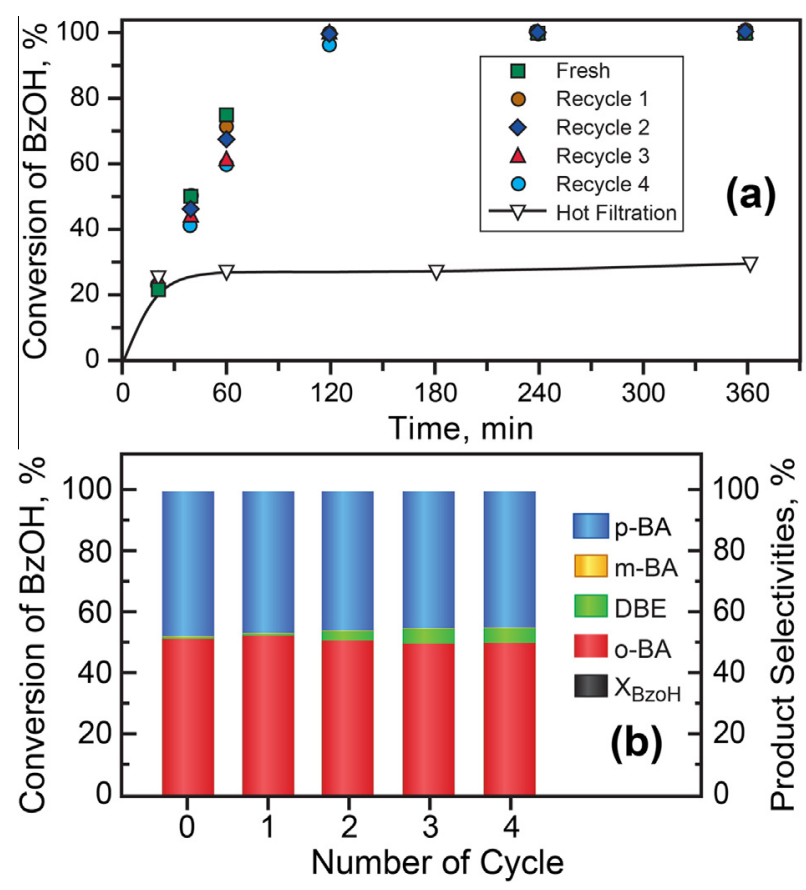

Fig. 15. (a) Recycle activity and hot-filtration studies, and (b) product selectivities at $6 \mathrm{~h}$, for Zr-KIT-5(25) catalyst at $130{ }^{\circ} \mathrm{C}$; reaction conditions: anisole $=100 \mathrm{mmol}$, $\mathrm{BzOH}=10 \mathrm{mmol}$, dodecane $=2 \mathrm{mmol}$.

DBE was noted after the 3rd cycle (Fig. 15b). Also only mild variations in the textural properties were noticed for both the fresh and recycled catalysts (see Fig. S3 and Table S1). Further, when the reaction mixture was hot-filtered after $20 \mathrm{~min}$, no significant 
changes in $\mathrm{BzOH}$ conversion was noticed in the filtrate. The foregoing results clearly demonstrate that the Zr-KIT-5 catalysts are reusable and stable under the reaction conditions.

\section{Conclusions}

Successful $\mathrm{Zr}$ incorporation into the framework of KIT-5 was achieved via a one-step direct hydrothermal synthesis procedure. The structural ordering and $\mathrm{Zr}$ incorporation were confirmed from complementary analytical techniques such as SAXS, N2 sorption, TEM, DRS-UV-Vis and XPS. Homogenous $\mathrm{Zr}$ dispersion was observed both from SEM and TEM analyses. All Zr-KIT-5 catalysts possess predominantly Lewis acid sites, with both the Lewis and Brønsted acid sites increasing with $\mathrm{Zr}$ content. The $\mathrm{Zr}$-KIT-5 materials show facile and stable activity for anisole alkylation with benzyl alcohol leading mainly to mono-alkylated products, outperforming other acidic mesoporous catalysts reported in the literature. Our results suggest that the alkylation activity is dependent on both the number and nature of the acid sites. Thus, Zr-KIT-5 materials show promise as environmentally superior alternatives to conventional Friedel-Crafts alkylation catalysts.

\section{Acknowledgments}

The authors acknowledge financial support by the U.S. Department of Agriculture under the National Institute of Food and Agriculture Grant No. 2011-10006-30362.

\section{References}

[1] G.A. Olah, Friedel-Crafts Chemistry; Interscience Monographs on Organic Chemistry, Wiley, 1973.

[2] G. Sartori, R. Maggi, Update 1 of: use of solid catalysts in Friedel-Crafts acylation reactions, Chem. Rev. 111 (2011) PR181.

[3] H. Dong, L. Shi, Alkylation of toluene with T-butyl alcohol over zeolite catalysts, Ind. Eng. Chem. Res. 49 (2010) 2091.

[4] A.F. Bidart, A.S. Borges, L. Nogueira, E. Lachter, C.A. Mota, Iron-exchanged zeolite as effective catalysts for Friedel-Crafts alkylation with alkyl halides, Catal. Lett. 75 (2001) 155.

[5] T. Odedairo, S. Al-Khattaf, Comparative study of zeolite catalyzed alkylation of benzene with alcohols of different chain length: H-ZSM-5 versus mordenite, Chall. Nanoporous Layer Mater. Catal. 204 (2013) 73.

[6] Z. Da, Z. Han, P. Magnoux, M. Guisnet, Liquid-phase alkylation of toluene with long-chain alkenes over HFAU and HBEA zeolites, Appl. Catal. Gen. 219 (2001) 45.

[7] B. Coq, V. Gourves, F. Figuéras, Benzylation of toluene by benzyl chloride over protonic zeolites, Appl. Catal. Gen. 100 (1993) 69.

[8] V. Choudhary, S. Jana, B.P. Kiran, Alkylation of benzene by benzyl chloride over H-ZSM-5 zeolite with its framework Al completely or partially substituted by Fe or Ga, Catal. Lett. 59 (1999) 217.

[9] K. Leng, S. Sun, B. Wang, L. Sun, W. Xu, Y. Sun, Benzylation of benzene with benzyl chloride on iron-containing mesoporous mordenite, Catal. Commun. 28 (2012) 64

[10] Y. Sun, R. Prins, Friedel-crafts alkylations over hierarchical zeolite catalysts, Appl. Catal. Gen. 336 (2008) 11.

[11] H. Jin, M.B. Ansari, E.-Y. Jeong, S.-E. Park, Effect of mesoporosity on selective benzylation of aromatics with benzyl alcohol over mesoporous ZSM-5, J. Catal. 291 (2012) 55.

[12] A. Vinu, D.P. Sawant, K. Ariga, M. Hartmann, S.B. Halligudi, Benzylation of benzene and other aromatics by benzyl chloride over mesoporous AlSBA-15 catalysts, Microporous Mesoporous Mater. 80 (2005) 195.

[13] A. Vinu, D.P. Sawant, K. Ariga, K.Z. Hossain, S.B. Halligudi, M. Hartmann, M. Nomura, Direct synthesis of well-ordered and unusually reactive FeSBA-15 mesoporous molecular sieves, Chem. Mater. 17 (2005) 5339.

[14] F. Adam, A.E. Ahmed, The benzylation of xylenes using heterogeneous catalysts from rice husk ash silica modified with gallium, Indium and Iron, Chem. Eng. J. 145 (2008) 328.

[15] A. Ramanathan, R. Maheswari, D.H. Barich, B. Subramaniam, Niobium incorporated mesoporous silicate, Nb-KIT-6: synthesis and characterization, Microporous Mesoporous Mater. 190 (2014) 240.
[16] A. Ramanathan, R. Maheswari, B.P. Grady, D.S. Moore, D.H. Barich, B. Subramaniam, Tungsten-incorporated cage-type mesoporous silicate: WKIT-5, Microporous Mesoporous Mater. 175 (2013) 43.

[17] R. Maheswari, M.P. Pachamuthu, A. Ramanathan, B. Subramaniam, Synthesis, characterization and epoxidation activity of tungsten-incorporated SBA-16 (W-SBA-16), Ind. Eng. Chem. Res. (2014).

[18] Q. Pan, A. Ramanathan, W.K. Snavely, R.V. Chaudhari, B. Subramaniam, Synthesis and dehydration activity of novel Lewis acidic ordered mesoporous silicate: Zr-KIT-6, Ind. Eng. Chem. Res. 52 (2013) 15481.

[19] Q. Pan, A. Ramanathan, W. Kirk Snavely, R. Chaudhari, B. Subramaniam, Intrinsic kinetics of ethanol dehydration over Lewis acidic ordered mesoporous silicate, Zr-KIT-6, Top. Catal. 57 (2014) 1407.

[20] M.H.C. De la Cruz, M.A. Abdel-Rehim, A.S. Rocha, J.F.C. da Silva, A. da Costa Faro Jr., E.R. Lachter, Liquid phase alkylation of anisole by benzyl alcohol catalyzed on alumina-supported Niobia, Catal. Commun. 8 (2007) 1650.

[21] A.S. Rocha, A.M.S. Forrester, M.H.C. de la Cruz, C.T. da Silva, E.R. Lachter, Comparative performance of niobium phosphates in liquid phase anisole benzylation with benzyl alcohol, Catal. Commun. 2008 (1959) 9.

[22] K. Okumura, K. Yamashita, M. Hirano, M. Niwa, The active and reusable catalysts in the benzylation of anisole derived from a heteropoly acid, J. Catal. 234 (2005) 300.

[23] Y. Rao, M. Trudeau, D. Antonelli, Sulfated and phosphated mesoporous Nb oxide in the benzylation of anisole and toluene by benzyl alcohol, J. Am. Chem. Soc. 128 (2006) 13996.

[24] Z. Miao, H. Zhao, H. Song, L. Chou, Ordered mesoporous zirconium oxophosphate supported tungsten oxide solid acid catalysts: the improved Bronsted acidity for benzylation of anisole, RSC Adv. 4 (2014) 22509.

[25] J. Li, Y. Zhou, D. Mao, G. Chen, X. Wang, X. Yang, M. Wang, L. Peng, J. Wang, Heteropolyanion-based ionic liquid-functionalized mesoporous copolymer catalyst for Friedel-Crafts benzylation of arenes with benzyl alcohol, Chem. Eng. J. 254 (2014) 54.

[26] Y.T. Hsu, W.L. Chen, C.M. Yang, Co-condensation synthesis of aminopropylfunctionalized KIT-5 mesophases using carboxy-terminated triblock copolymer, J. Phys. Chem. C 113 (2009) 2777.

[27] F. Kleitz, D. Liu, G.M. Anilkumar, I.-S. Park, L.A. Solovyov, A.N. Shmakov, R. Ryoo, Large cage face-centered-cubic Fm3m mesoporous silica: synthesis and structure, J. Phys. Chem. B 107 (2003) 14296.

[28] C. Anand, S.V. Priya, G. Lawrence, D.S. Dhawale, S. Varghese, M.A. Wahab, K.S. Prasad, A. Vinu, Cage type mesoporous ferrosilicate catalysts with 3D structure for benzylation of aromatics, Chall. Nanoporous Layer Mater. Catal. 204 (2013) 125.

[29] C. Anand, P. Srinivasu, G.P. Mane, S.N. Talapaneni, M.R. Benzigar, S. Al-deyab Salem, Y. Sugi, A. Vinu, Direct synthesis and characterization of highly ordered cobalt substituted KIT-5 with 3D nanocages for cyclohexene epoxidation, Microporous Mesoporous Mater. 167 (2013) 146.

[30] C. Anand, P. Srinivasu, G.P. Mane, S.N. Talapaneni, D.S. Dhawale, M.A. Wahab, S.V. Priya, S. Varghese, Y. Sugi, A. Vinu, Preparation of mesoporous titanosilicate molecular sieves with a cage type 3D porous structure for cyclohexene epoxidation, Microporous Mesoporous Mater. 160 (2012) 159.

[31] C.Y. Wu, Y.T. Hsu, C.M. Yang, Structural modulation of cage-like mesoporous KIT-5 silica by post-synthesis treatments with ammonia and/or sulfuric acid, Microporous Mesoporous Mater. 117 (2009) 249.

[32] A. Ramanathan, M.C. Castro Villalobos, C. Kwakernaak, S. Telalovic, U. Hanefeld, Zr-TUD-1: a Lewis acidic, three-dimensional, mesoporous, zirconium-containing catalyst 14 (2008) 961.

[33] A. Ramanathan, B. Subramaniam, R. Maheswari, U. Hanefeld, Synthesis and characterization of zirconium incorporated ultra large pore mesoporous silicate, Zr-KIT-6, Microporous Mesoporous Mater. 167 (2013) 207.

[34] M.P. Pachamuthu, V.V. Srinivasan, R. Maheswari, K. Shanthi, A. Ramanathan, Lewis acidic ZrTUD-1 as catalyst for tert-butylation of phenol, Appl. Catal. Gen. 462-463 (2013) 143.

[35] M.S. Morey, G.D. Stucky, S. Schwarz, M. Froba, Isomorphic substitution and postsynthesis incorporation of zirconium into MCM-48 mesoporous silica, J. Phys. Chem. B 103 (1999) 2037.

[36] B.L. Newalkar, J. Olanrewaju, S. Komarneni, Microwave-hydrothermal synthesis and characterization of zirconium substituted SBA-15 mesoporous silica, J. Phys. Chem. B 105 (2001) 8356.

[37] S. Chen, Y. Yin, D. Wang, Formation of ring-like Si-O-Zr bonds at intergranular interfaces in silica-doped zirconia, J. Am. Ceram. Soc. 1041 (2005) 88.

[38] H.J.M. Bosman, A.P. Pijpers, A.W.M.A. Jaspers, An X-ray photoelectron spectroscopy study of the acidity of $\mathrm{SiO}_{2}-\mathrm{ZrO}_{2}$ mixed oxides, J. Catal. 161 (1996) 551.

[39] Y. Zhu, G.-K. Chuah, S. Jaenicke, Selective Meerwein-Ponndorf-Verley reduction of unsaturated aldehydes over Zr-zeolite beta, J. Catal. 241 (2006) 25.

[40] C.R. Kumar, P.S.S. Prasad, N. Lingaiah, Heteropoly tungstate supported on tin oxide catalysts for liquid phase benzylation of anisole with benzyl alcohol, Appl. Catal. Gen. 384 (2010) 101.

[41] M.H.C. De la Cruz, J.F.C. da Silva, E.R. Lachter, Catalytic activity of niobium phosphate in the Friedel-Crafts reaction of anisole with alcohols, Catal. Today 118 (2006) 379.

[42] Z. Miao, H. Song, H. Zhao, L. Xu, L. Chou, One-pot synthesis of mesoporous ZrPW solid acid catalyst for liquid phase benzylation of anisole, Catal. Sci. Technol. 4 (2014) 838. 